\title{
Current concepts in combination therapy for the treatment of hypertension: combined calcium channel blockers and RAAS inhibitors
}

This article was published in the following Dove Press journal:

Integrated Blood Pressure Control

20 November 2009

Number of times this article has been viewed

\author{
Alberto F Rubio-Guerra' \\ David Castro-Serna ${ }^{2}$ \\ Cesar I Elizalde Barrera ${ }^{2}$ \\ Luz M Ramos-Brizuela ${ }^{2}$ \\ 'Metabolic and Research Clinic, \\ ${ }^{2}$ Internal Medicine Department, \\ Hospital General de Ticomán SS DF, \\ México
}

\begin{abstract}
Recent guidelines for the management of hypertension recommend target blood pressures $<140 / 90 \mathrm{mmHg}$ in hypertensive patients, or $<130 / 80 \mathrm{mmHg}$ in subjects with diabetes, chronic kidney disease, or coronary artery disease. Despite the availability and efficacy of antihypertensive drugs, most hypertensive patients do not reach the recommended treatment targets with monotherapy, making combination therapy necessary to achieve the therapeutic goal. Combination therapy with 2 or more agents is the most effective method for achieving strict blood pressure goals. Fixed-dose combination simplifies treatment, reduces costs, and improves adherence. There are many drug choices for combination therapy, but few data are available about the efficacy and safety of some specific combinations. Combination therapy of calcium antagonists and inhibitors of the renin-angiotensin-aldosterone system (RAAS) are efficacious and safe, and have been considered rational by both the JNC 7 and the 2007 European Society of Hypertension - European Society of Cardiology guidelines for the management of arterial hypertension. The aim of this review is to discuss some relevant issues about the use of combinations with calcium channel blockers and RAAS inhibitors in the treatment of hypertension.
\end{abstract}

Keywords: hypertension, calcium channel blockers, renin-angiotensin-aldosterone system inhibitors, fixed-dose combination, adherence

\section{Introduction}

Hypertension is still a major public health issue, affecting millions of patients worldwide. Although control rates have improved during the past years, the actual rate is still unacceptably low, and control rates in more vulnerable populations, such as persons with diabetes mellitus, are even lower. Because hypertension is a major risk factor for cardiac and cerebrovascular events, patients with uncontrolled or poorly controlled blood pressure (BP) are at high risk for serious morbidity and mortality. ${ }^{1,2}$

Hypertension has a prevalence of $30.1 \%$ in Mexico (and only $19 \%$ of these cases are controlled), and its prevalence continues to increase; $49 \%$ of hypertensive patients in Mexico are obese (body mass index [BMI] $>30 \mathrm{~kg} / \mathrm{m}^{2}$ ). ${ }^{3}$

Optimal BP control could prevent a high percentage of coronary heart disease events, and early BP control significantly reduces the risk of stroke and cardiovascular events. ${ }^{1}$

Despite the availability and efficacy of antihypertensive drugs, almost $70 \%$ of hypertensive patients do not reach the recommended treatment target of $<140 / 90 \mathrm{mmHg}$ with monotherapy, and only a small proportion of high risk patients reaches the goal of $<130 / 80 \mathrm{mmHg}$ (in patients with diabetes, chronic kidney disease, or coronary artery disease), making combination therapy necessary to achieve these targets with minimal
Correspondence: Alberto Francisco Rubio-Guerra

Motozintla \# 30, Col Letran valle, México D.F. C.P. 03600

$\mathrm{Tel} / \mathrm{Fax}+525555393584$

Email clinhta@hotmail.com submit your manuscript | www.dovepress.com

Dovepress 
adverse effects. The extra BP reduction from combining drugs from two different classes is approximately 2 to 5 times greater than doubling the dose of one drug. ${ }^{4,5}$ In both cases, combination therapy results in more effective and more prompt BP lowering, at lower doses. Compared with free combinations (drugs in different pills), fixed-dose regimens (both drugs in the same pill) have the advantages of greater convenience and potentially reduced costs, both of which may translate into improved adherence and superior BP reductions. ${ }^{6}$ Indeed both the Seventh Report of the Joint National Committee on Prevention, Detection, Evaluation and Treatment of High Blood Pressure (JNC7), ${ }^{1}$ and the 2007 European Society of Hypertension and the European Society of Cardiology guidelines (ESHCG) for the management of arterial hypertension, ${ }^{7}$ recommended considering using 2 or 3 drugs or combination therapy for patients in whom the probability of achieving BP control with monotherapy is low, such as patients with systolic BP higher than $20 \mathrm{mmHg}$ or diastolic BP higher than $10 \mathrm{mmHg}$ from the therapeutic goal. Table 1 describes the advantages of combination therapy.

Clinicians have many drug choices for combination therapy, but few data are available for the efficacy and safety of some specific combinations; this is especially true for fixeddose combinations. Most fixed-dose combinations include a diuretic, and have been shown to provide BP reductions greater than those seen with monotherapy. ${ }^{5}$ Combination therapy of calcium antagonists plus inhibitors of the reninangiotensin-aldosterone system (RAAS) are efficacious and safe, and represent a new addition to the available antihypertensive treatment options. ${ }^{6,8}$ This combination therapy acts on several pathways that increase BP in hypertensive patients, ie, blocking the renin-angiotensin system, relaxing vascular smooth muscle, with a reduction of peripheral resistance, and both inhibitors of the RAAS and calcium antagonists can counteract the hypertensive effect of endothelin-1. ${ }^{9}$ The 2 drug families improve endothelial function and insulin resistance. ${ }^{6,9}$ These combinations have been considered rational by both

Table I Advantages of combining antihypertensive agents Combination of 2 agents at low doses gives greater blood pressure reductions than higher dose of I drug

Fewer adverse effects

Blockade of several pathways that increase blood pressure

Increased protection of target organs

Prompt blood pressure control

Effects beyond their antihypertensive actions
Table 2 Currently available fixed-dose combinations

\begin{tabular}{ll}
\hline ACE inhibitor and CCB & References \\
\hline Ramipiril/felodipine & \\
Benazepril/amlodipine & $11,25,35$ \\
Delapril/manidipine & 34 \\
Trandolapril/verapamil & $13,14,26,28,30$ \\
ARB and CCB & \\
Valsartan/amlodipine & 18 \\
\hline
\end{tabular}

Abbreviations: $\mathrm{ACE}$, angiotensin converting enzyme; $\mathrm{ARB}$, angiotensin receptor blocker; $\mathrm{CCB}$, calcium channel blocker.

the JNC $7^{1}$ and the ESHCG. ${ }^{7}$ Table 2 shows the fixed-dose combinations of a RAAS inhibitor with the currently available calcium channel blockers (CCB).

In this review we analyze the combination therapy of CCB with inhibitors of the RAAS: the data on its efficacy, safety and advantages beyond its antihypertensive effect, with emphasis on fixed-dose combinations.

\section{Therapeutic efficacy}

A combination therapy of calcium antagonists plus inhibitors of the RAAS provides higher antihypertensive efficacy and is usually well tolerated. Several trials have assessed the potential of such combinations. ${ }^{9}$

The combination of these classes of drugs may be superior to other combinations for target organ protection, a metaanalysis having shown that angiotensin-converting enzyme (ACE) inhibitors appear superior to $\mathrm{CCB}$ for prevention of coronary heart disease, whereas $\mathrm{CCB}$ appear superior to $\mathrm{ACE}$ inhibitors for prevention of stroke. Therefore, the combination of these agents could offer the rationale for a broadspectrum cardiovascular and cerebrovascular prevention. ${ }^{10}$

In an Antihypertensive and Lipid-Lowering Treatment to Prevent Heart Attack Trial (ALLHAT) subanalysis, the ACE inhibitor lisinopril showed a superior effect over the $\mathrm{CCB}$ for heart failure prevention, but the CCB amlodipine was superior to the ACE inhibitor for stroke prevention, ${ }^{11}$ findings that agree with those of the previous meta-analysis. ${ }^{10}$

\section{ACE inhibitors/calcium antagonists combinations}

The hemodynamic profile of this combination is peripheral vasodilatation without sodium and fluid retention, with reduction of peripheral resistance and improvement of left ventricular function. ${ }^{9}$

In the Avoiding Cardiovascular Events Through Combination Therapy in Patients Living With Systolic Hypertension (ACCOMPLISH) trial, ${ }^{12}$ the first trial designed to compare 
the fixed-dose combination of an ACE inhibitor plus a CCB with another combination, the antihypertensive efficacy of the fixed-dose combination benazepril/amlodipine was compared with that of the combination benazepril/hydrochlorothiazide in more than 11,400 high risk patients aged $\geq 55$ years. After a follow-up of 36 months (the study was finished early), both treatments reached the BP goal of less than 140/90 $\mathrm{mmHg}$ in more than $75 \%$ of patients. However, hard cardiovascular (CV) endpoints ( $\mathrm{CV}$ death, stroke, and myocardial infarction) were reduced by $20 \%(P=0.007)$ in the benazepril/amlodipine group, and a cardiovascular morbidity/mortality reduction of $20 \%(P=0.0002)$ in that group was noted, too.

In the Anglo Scandinavian Cardiac Outcomes Trial-Blood Pressure Lowering Arm (ASCOT-BPLA), the amlodipine-based therapy (with perindopril added if necessary, although not in fixed-dose combination) was compared with an atenolol-based therapy (with bendroflumethiazide added if necessary) in 19,257 high risk hypertensive patients. ${ }^{13}$ After a median 5.5 years of follow-up, amlodipine/perindopril was more effective than atenolol/thiazide in decreasing fatal and nonfatal stroke, total cardiovascular events, and all-cause mortality (all secondary endpoints). The amlodipine/perindopril group also had a significantly lower incidence of new-onset diabetes compared with the atenolol/thiazide group.

The INternational VErapamil SR/trandolapril Study (INVEST), a verapamil SR-based treatment strategy, with trandolapril added, was as effective as an atenolol-based treatment strategy (which also included the addition of trandolapril) in reducing the risk of the primary outcomes of death (all-cause), nonfatal myocardial infarction, or nonfatal stroke in patients with hypertension and coronary artery disease. ${ }^{14}$ In the INVEST trial, the verapamil/ trandolapril group also had a significantly lower incidence of new-onset diabetes compared with the atenolol/trandolapril group.

We have found that the fixed-dose combination of trandolapril/verapamil is an effective and safe option for the management of stage 2 hypertension in Mexican patients uncontrolled by monotherapy, ${ }^{15}$ with a low incidence of adverse effects ( 1 case of constipation).

Based on the papers reviewed above, the combination of an ACE inhibitor with a CCB (dihydropiridine or nondihydropiridine) is effective and safe for the management of hypertensive patients, including subjects uncontrolled by monotherapy, and obese and high risk patients. This combination has been shown to reduce cardiovascular and cerebrovascular endpoints and is well tolerated.
The metabolic advantages of the combination will be commented on later.

It is important to note that because ACE inhibitors produce arterial and venous vasodilation, they reduce the incidence of CCB-induced ankle edema, and counteract the RAAS and sympathetic stimulation promoted by $\mathrm{CCB} ;{ }^{16}$ therefore the combination also has a lower incidence of adverse effects than monotherapy.

\section{Combination of a CCB and an angiotensin receptor blocker}

The hemodynamic profile of this combination is also peripheral vasodilatation without sodium and fluid retention, with reduction of peripheral resistance and improvement of left ventricular function. ${ }^{4}$

Although this combination is less studied than combinations that include an ACE inhibitor, several recently published short-term studies assessing the efficacy and tolerability of amlodipine plus various angiotensin receptor blockers (ARB) in patients with mild to moderate hypertension show promising results, but no head to head studies of these combinations have been published. ${ }^{17}$

In a randomized, double-blind study, the safety and efficacy of the combination of amlodipine/valsartan in patients with stage 2 hypertension was compared with the combination of lisinopril/hydrochlorothiazide, ${ }^{18}$ both regimens reduced BP significantly after a 6 weeks of follow-up, and there were no differences between them.

In the Exforge in Failure after Single Therapy (EX-FAST) study, 894 patients uncontrolled with monotherapy were switched to amlodipine/valsartan, and followed for 16 weeks, when the therapeutic goals $(<140 / 90 \mathrm{mmHg}$ or $<130 / 80 \mathrm{mmHg}$ for diabetes patients) were reached by $74.8 \%$ of patients. ${ }^{19}$

In the Combination of Olmesartan medoximil and Amlodipine besylate in Controlling High blood pressure $(\mathrm{COACH})$ trial, the combination of olmesartan/amlodipine was superior to higher doses of each drug in monotherapy for BP reductions in 1940 patients with mild to severe hypertension after 8 weeks of treatment; ${ }^{20}$ the combination was well tolerated.

In a recent study that included 1461 patients followed for 8 weeks, the combination of telmisartan/amlodipine significantly decreased BP in patients with hypertension stage 1 or $2 .^{21}$

$\mathrm{ARB}$ also reduce the incidence of $\mathrm{CCB}$-induced ankle edema, perhaps in the same way as do ACE inhibitors; ${ }^{17}$ therefore this combination has fewer side effects than the monotherapy. 
Although less studied than combinations of an ACE inhibitor and a calcium antagonist, and without results on hard cardiovascular endpoints and from long-term randomized trials, the combination of an $\mathrm{ARB}$ and a $\mathrm{CCB}$ seems to be effective and safe for the management of uncontrolled hypertensive patients.

\section{Aliskiren plus CCB}

Two recent studies have evaluated the effect of the direct renin inhibitor aliskiren/amlodipine (not in fixed-dose). The first assessed the long-term efficacy and safety of aliskiren in comparison with the diuretic hydrochlorothiazide in 1124 patients with essential hypertension; in both groups amlodipine was added on week 12 , and after a follow-up of 52 weeks, aliskiren/amlodipine treatment provided significantly greater BP reductions than the respective hydrochlorothiazide (with amlodipine added) regimen; aliskiren-based therapy was well tolerated. ${ }^{22}$

In the second study with 556 patients with hypertension stage 1 or $2,{ }^{23}$ the combination of aliskiren/amlodipine effectively reduced BP after a 52 weeks' follow-up, particularly in patients with hypertension stage 2 , with a low incidence of ankle edema.

As the available information for the combination of aliskiren and CCB is limited, especially in a fixed-dose formulation, more studies with this combination are needed.

\section{Effects beyond their antihypertensive actions}

\section{Anti-inflammatory effects}

Both RAAS inhibitors ${ }^{24}$ and $\mathrm{CCB}^{25}$ have shown an anti-inflammatory effect, mainly because they decrease some mediators of inflammation.

Siragy found that the combination of benazepril/ amlodipine produced a greater reduction in tumor necrosis factor- $\alpha$ and interleukin- 6 than either drug alone in ischemic rats, providing more evidence for the anti-inflammatory synergism between an ACE inhibitor with a CCB. ${ }^{26}$

We have shown that although trandolapril and its fixed-dose combination with verapamil reduce the levels of circulating soluble adhesion molecules, trandolapril with verapamil (TV) produces a greater reduction in VCAM-1 levels than trandolapril alone in type 2 diabetes patients with hypertension. ${ }^{27}$

As these mediators participate in the development of target organ damage in diabetes and hypertension, ${ }^{28}$ it is possible that the protection unrelated to the antihypertensive effect given by these combinations may be mediated, at least in part, by this anti-inflammatory effect. This requires further investigation.

\section{Metabolic effects}

As noted above, in both the ASCOT-BPLA ${ }^{13}$ and the INVEST $^{14}$ trials, the combination of a RAAS inhibitor with a CCB shows a significantly lower incidence of new-onset diabetes; however, in these trials they were compared with a combination that included a $\beta$ blocker (INVEST), or the combination of a $\beta$ blocker with a thiazide (ASCOTBPLA). Several studies have demonstrated increased risk of newonset diabetes in patients treated with both thiazide diuretics or $\beta$ blockers. $^{7}$

In the Study of Trandolapril-Verapamil SR And Insulin Resistance (STAR), 240 patients with impaired glucose tolerance, normal kidney function, and hypertension received the fixed-dose combination of TV or losartan/ hydrochlorothiazide (LH), with a follow-up of 1 year. At the end of the study, TV reduced significantly the risk of newonset diabetes compared with LH. ${ }^{29}$

In the STAR Long-Term Extension Trial (STAR-LET), patients previously randomized to LH in the STAR trial were switched to TV therapy in a 6-month open-label extension. ${ }^{30}$ At the end of the study, there was a reversal on half of the cases of new-onset diabetes that occurred during the original trial in the LH group, once they were switched to TV.

The findings of these 2 trials were attributed to the presence of hydrochlorothiazide in the LH group, and the persistence of its diabetogenic effect in spite of the inhibition of RAAS with losartan. However, we found that normotensive diabetes patients treated with the fixed-dose TV combination (for nephroprotection) reached a better fasting glycemic control than normotensive diabetes patients treated with monotherapy with trandolapril after 6 months of treatment. In that trial no patient received diuretics, ${ }^{31}$ leading us to hypothesize that the fixed-dose TV combination may have a role in glycemic control unrelated to its antihypertensive effect.

We found that fixed-dose TV produces a greater reduction in resistin levels than trandolapril alone. ${ }^{32}$ Resistin is an adipocitokyne that antagonizes the effect of insulin on glucose metabolism and favors the development of diabetes. ${ }^{33}$ This effect may explain, at least in part, the favorable metabolic actions of TV, but this issue requires further investigation.

It is important to note that Roca-Cusachs et $\mathrm{al}^{34}$ found that after 12 weeks of treatment of 304 hypertensive diabetes patients with the fixed-dose combination manidipine/delapril 
versus the combination losartan/hydrochlorothiazide, more patients in the losartan/hydrochlorothiazide group suffered a non-significant increase in $\mathrm{HbA}_{1 \mathrm{c}}$ levels $(7.9 \%$ in the manidipine/delapril group vs $17.4 \%$ in the losartan/ hydrochlorothiazide group).

ESHCG further recommend use of an ACE inhibitor or an ARB in patients with metabolic syndrome or at high risk for the development of diabetes, ${ }^{7}$ and when a second agent is needed, a CCB is suggested as an appropriate option (dihydropiridine or non-dihydropiridine).

In type 2 diabetes patients, RAAS inhibitor/CCB combination therapy may offer benefits to patients beyond BP lowering.

In the Fosinopril versus Amlodipine Cardiovascular Events randomized Trial (FACET), an open label, prospective study, ${ }^{35} 380$ hypertensive type 2 diabetes patients were randomized to fosinopril or amlodipine, and if BP was not controlled, the other study drug was added. After 3.5 years of treatment, $28.4 \%$ of patients received both agents, and those patients on combination therapy had a lower risk of acute myocardial infarction, hospitalized angina, and stroke (all secondary endpoints of the study), compared with monotherapy.

As in FACET, in ACCOMPLISH ${ }^{12}$ and ASCOTBPLA ${ }^{13}$ combination therapy of a CCB with a RAAS inhibitor reduced the incidence of cardiovascular complications and stroke compared with other therapies (monotherapy or combined therapy). The benefits of the combination of a RAAS inhibitor plus a CCB that lead to cardiovascular prevention are clear, but the reasons for such outcomes are not.

The pathways that explain the $\mathrm{CV}$ and cerebrovascular outcomes with the combination of a RAAS inhibitor with a $\mathrm{CCB}$ may be related to the organ protective properties of both classes of drugs plus those of the combination, ie, anti-inflammatory, ${ }^{26,27}$ antioxidative, and antiatherosclerotic actions, and central aortic pressure reduction. ${ }^{8}$ In a small study of patients with hypertension and type 2 diabetes, fixed-dose combination therapy with amlodipine/benazepril improved large-artery compliance to a greater extent than did monotherapy with enalapril, despite attainment of similar BP levels. Decreased arterial compliance may frequently precede cardiovascular events and serve as a sensitive marker for at-risk patients. ${ }^{36}$

\section{Kidney protection}

Several studies in diabetes patients show that RAAS inhibitors ${ }^{37}$ and nondihydropiridine $\mathrm{CCB}^{38}$ decrease proteinuria and the rate of creatinine clearance decline; therefore a combination of a RAAS inhibitor with a CCB should have a higher renoprotective effect than monotherapy.

In a randomized, open label study in 44 hypertensive type 2 diabetes patients with nephropathy, the trandolapril/ verapamil combination produced a greater reduction in proteinuria over either agent alone at 1 year. When changes in $\mathrm{BP}$ were correlated, the reduction in proteinuria could not be differentiated from the degree of BP reduction. ${ }^{39}$

We found that the fixed-dose combination of TV effectively reduced albuminuria in 30 hypertensive type 2 diabetes patients whose hypertension was unresponsive to at least 6 months of antihypertensive treatment with an ACE inhibitor; ${ }^{40}$ however, because in this study BP had an important reduction after the study duration of 6 months, we could not ascertain whether the reduction in albuminuria was secondary to the BP reduction or to a pleiotropic effect of the combination.

Our group also found that the same fixed-dose combination of TV reduced albuminuria to a greater extent than did monotherapy with trandolapril (and did not alter the glomerular filtration rate, which was significantly reduced by trandolapril), after 6 months of treatment in 60 type 2 diabetes normotensive patients with albuminura $>300 \mathrm{mg} / 24$ hours, and who had not received prior treatment with antihypertensive drugs. ${ }^{32}$ We did not record a significant change in BP with the treatment.

In the Bergamo Nephrologic Diabetes Complications Trial (BENEDICT), 1204 hypertensive patients with type 2 diabetes and normoalbuminuria were randomly assigned to receive trandolapril, verapamil, the combination of both drugs or placebo during 3.6 years. The combination TV significantly delayed the onset of microalbuminuria (by a factor of 2.6), whereas trandolapril monotherapy delayed the onset of microalbuminuria by a factor of 2.1 and verapamil did not delay the onset of microalbuminuria. ${ }^{41}$

In a small study in 15 type 1 diabetes normotensive patients with incipient diabetic nephropathy, ${ }^{42}$ the combination TV significantly decreased urinary albumin excretion within 1 year of treatment (a significant decrease of fasting plasma glucose was also noted).

We found that the fixed-dose combination TV produced a greater reduction in albuminuria than trandolapril alone in 40 hypertensive type 2 diabetes patients after 3 months of treatment, ${ }^{27}$ and that reduction was unrelated to the decrease in BP.

When the effects of combinations that include a dihydropiridine CCB have been explored for the prevention or management of diabetic nephropathy, results have been controversial. 
In the GaUging Albuminuria Reduction with lotrel in Diabetic patients with hypertension (GUARD) study, after 1 year of treatment, ${ }^{43}$ the combination benazepril/ hydrochlorothiazide resulted in a greater reduction of albuminuria compared with the combination benazepril/ amlodipine in 332 hypertensive type 2 diabetes patients.

The combination fosinopril/amlodipine provided a greater antialbuminuric effect than both monotherapies in 453 hypertensive type 2 diabetes patients after 48 months of treatment; however, the combination therapy had a greater antihypertensive effect, which could explain the results. In this study, ${ }^{44}$ cardiovascular outcomes were lower in the combination group.

Two studies have compared the effect of combinations of dihydropiridine versus a non-dihydropiridine CCB plus a RAAS inhibitor in albuminuria.

In a randomized trial, 45,304 type 2 diabetes hypertensive patients received the combination TV or benazepril/amlodipine. After 36 weeks' follow-up, both treatments reduced albuminuria, but neither combination was superior to the other.

In the Verapamil versus Amlodipine in Nondiabetic Nephropathies Treated with Trandolapril (VVANNTT) study, ${ }^{46}$ proteinuria was reduced significantly after 1 month of monotherapy with trandolapril in non-diabetes patients. At the end of this period, patients were randomized to receive, in a double-blind fashion, either amlodipine or verapamil. After 8 months of follow-up, there was a slight but nonsignificant reduction in proteinuria in both groups.

A small study in hypertensive type 2 diabetes patients with nephropathy compared the combination candesartan/ amlodipine with temocapril/candesartan. Both regimens reduced $\mathrm{BP}$ to the same extent, ${ }^{47}$ and the temocapril/ candesartan combination showed a greater antiproteinuric effect. However, this combination was associated with an increase in serum potassium and with worsening of renal anemia. It is important to bear all this in mind in relation to the renal outcomes of the Ongoing Telmisartan Alone or in combination with Ramipril Global Endpoint Trial (ONTARGET). In this trial, although combination therapy of an ACE inhibitor with an ARB reduced proteinuria to a greater extent than monotherapy, ${ }^{48}$ it also worsened major renal outcomes. This result raises the possibility that a combination of a RAAS inhibitor with a CCB may be safer than the combination of an ACE inhibitor with an ARB.

Based on the information available, the combination of a RAAS inhibitor plus a CCB (dihydropiridine or non-dihydropiridine) is effective and safe for renoprotection in diabetes patients (hypertensive or normotensive), and useful when a greater antiproteinuric effect is needed. The fixed dose combination of an ACE inhibitor with verapamil is able to avoid the evolution from normoalbuminury to microalbuminury. But the protective role of these combinations in non-diabetes nephropathies is unclear.

\section{Fixed-dose combination advantages (Table 3)}

The BP control rate in the United States is $27 \%$ to $29 \%{ }^{48}$ and that in Mexico is about 19\%. Therefore, about $70 \%$ of patients will need combinations of antihypertensive drugs to reach the recommended goals. ${ }^{3}$

Poor compliance to medication contributes to these low control rates. Complexity of treatment, and polypharmacy, and the number of doses to be taken during the day are determinants of poor compliance. ${ }^{49}$

A combination of agents from different drug classes is 2 to 5 times more effective in lowering BP than increasing the dose of monotherapy. ${ }^{4,5}$ In addition, doubling the dose of monotherapy reduces coronary events by $29 \%$ and cerebrovascular events by $40 \%$, whereas combining 2 drugs with a different mechanism of action would reduce coronary events by $40 \%$, and stroke by $54 \% .^{5}$

A low dose of 2 agents reduces adverse events, too, not only those that are dose-related, but also because the mechanism of action of one drug may interfere with the pathways for adverse effects of the second drug, ie, diuretics avoid the water retention induced by vasodilators, RAAS inhibitors avoid the RAAS activation produced by diuretics and CCB. ${ }^{47}$

Fixed-dose combinations may simplify the treatment regimen, and favor patient compliance; in fact, the risk of noncompliance to therapy in hypertensive patients is reduced by $24 \%(P<0.0001)$ by fixed-dose combinations compared with free drug combination regimens. ${ }^{49} \mathrm{~A}$ fixed-dose combination may also cost less than the individual components. ${ }^{9,47}$

The fixed-dose combination of a RAAS inhibitor with a CCB is an effective and safe option for the treatment of hypertensive patients who do not reach their BP goals. This combination facilitates compliance, and has a lower incidence of side effects and at a lower cost. However it has

Table 3 Advantages of fixed-dose combination of antihypertensive agents

Simplification of treatment

Reduction of costs

Improvement of compliance

Those described in Table I 
the inconvenience of being less flexible when dose needs to be adjusted, since usually there are only 1 or 2 presentations of each preparation.

\section{Conclusion}

Although hypertension is a major risk factor for cardiac and cerebrovascular events, and BP control reduces the risk of stroke and cardiovascular events, the actual control rate is unacceptably low, making combination therapy necessary to achieve therapeutic goals. A combination of agents from different classes is 2 to 5 times more effective in lowering BP than increasing the dose of monotherapy.

There are many drug choices for combination therapy. Combination therapy of CCB plus inhibitors of RAAS are efficacious and safe, and have been considered rational by both the JNC 7 and the ESHCG.

The combination of an inhibitor of the RAAS with a CCB (dihydropiridine or non-dihydropiridine) includes drugs with differing mechanism of action, and is effective and safe for the management of hypertensive patients because it produces additive BP lowering while minimizing side effects. The combination of agents from these 2 families has been shown to produce target organ protection. Several studies such as ACCOMPLISH and ASCOTBPLA have shown that this combination reduces cardiovascular morbidity and mortality, and new-onset diabetes.

The combination has also been shown to have a renoprotective action superior to monotherapy, and beneficial metabolic effects, which led the ESHCG to recommend this association in patients at high risk for developing diabetes, who require combination therapy to reach the therapeutic goals.

Fixed-dose combination increases compliance, simplifies treatment and reduces cost, and must be borne in mind when planning antihypertensive treatment in patients uncontrolled with monotherapy.

\section{Disclosures}

There are no conflicts of interest. However, AFRG is Fellow, and receives a grant from Consejo Nacional de Ciencia y Tecnologia (CONACYT) Mexico, a government office for research support.

\section{References}

1. The Seventh report of the Joint National Committee on Detection, Evaluation, and Treatment of High Blood pressure. JNC 7. Hypertension. 2003;42:1206-1252.

2. Ong KL, Cheung BMY, Man YB, et al. Prevalence, awareness, treatment, and control of hypertension among United States adults, 1999-2004. Hypertension. 2007;49:69-75.
3. Rosas M, Lara A, Pastelín G, Velásquez O, Martínez J, Mendez A Re-encuesta nacional de hipertensión arterial. Consolidación Mexicana de los factores de riesgo cardiovascular. Cohorte Nacional de Seguimiento. Arch Cardiol Mex. 2005;75:96-111.

4. Pimenta E, Oparil S. Fixed combinations in the management of hypertension: patient perspectives and rationale for development and utility of the olmesartan-amlodipine combination. Vasc Health Risk Manag. 2008;4:653-664.

5. Wald DS, Law M, Morris JK, Bestwick JP, Wald NJ. Combination therapy versus monotherapy in reducing blood pressure: meta-analysis on 11,000 participants from 42 trials. Am J Med. 2009;122:290-300.

6. Bakris GL. Combined therapy with a calcium channel blocker and an angiotensin ii type 1 receptor blocker. J Clin Hypertens. 2008; 10(1 Suppl 1):27-32.

7. The Task Force for the Management of Arterial Hypertension of the European Society of Hypertension and the European Society of Cardiology. Guidelines for the management of arterial hypertension. J Hypertens. 2007;25:105-188.

8. Dahlöf B. Management of cardiovascular risk with RAS inhibitor/ CCB combination therapy. J Hum Hypertens. 2009;23:77-85.

9. Rubio AF, Lozano JJ, Vargas G, Rodríguez L, Ramos LM, Escalante B. Efficacy of a fixed-dose combination of trandolapril-verapamil in obese hypertensive patients resistant to monotherapy. Clin Exp Hypertens. 2006;28:619-624

10. Verdecchia P, Reboldi G, Angeli F, et al. Angiotensin-converting enzyme inhibitors and calcium channel blockers for coronary heart disease and stroke prevention. Hypertension. 2005;46:386-392.

11. Llenen FH, Nwachuku CH, Black HR, et al. Clinical events in high-risk hypertensive patients randomly assigned to calcium channel blocker versus angiotensin-converting enzyme inhibitor in the Antihypertensive and Lipid-Lowering Treatment to Prevent Heart Attack Trial. Hypertension. 2006;48:374-384.

12. Jamerson K, Weber MA, Bakris GL, et al. Benazepril plus amlodipine or hydrochlorothiazide for hypertension in high-risk patients. $N \mathrm{Engl}$ J Med. 2008;359:2417-2428.

13. Dahlöf B, Sever PS, Poulter NR, et al. Prevention of cardiovascular events with an antihypertensive regimen of amlodipine adding perindopril as required versus atenolol adding bendroflumethiazide as required, in the Anglo-Scandinavian Cardiac Outcomes Trial-Blood Pressure Lowering Arm (ASCOT-BPLA): a multicentre randomized controlled trial. Lancet. 2005;366:895-906.

14. Pepine CJ, Handberg EM, Cooper-DeHoff RM, et al; for the INVEST Investigators. A calcium antagonist vs a non-calcium antagonist hypertension treatment strategy for patients with coronary artery disease (INVEST): a randomized controlled trial. JAMA. 2003;290:2805-2816.

15. Rubio AF, Arceo A. Lozano JJ, Vargas G, Rodríguez L, Ramos LM. Efficacy of a fixed-dose combination of trandolapril-verapamil in patients with stage- 2 hypertension inadequately controlled by monotherapy. Clin Drug Invest. 2005;25:445-451.

16. Fogari R, Malamani GD, Zoppi A, Mugellini A, Rinaldi A, Vanasia A. Effect of benazepril addition to amlodipine on ankle oedema and subcutaneous tissue pressure in hypertyensive patients. J Hum Hypertens. 2003; 17:207-212.

17. Parati G. Optimization of hypertension management: The role of angiotensin receptor blocker-calcium channel blocker combinations. J Cardiovasc Pharmacol. 2009;53:352-358.

18. Poldermans D, Glazer R, Karagiannis S, et al. Tolerability and blood pressure-lowering efficacy of the combination of amlodipine plus valsartan compared with lisinopril plus hydrochlorothiazide in adult patients with stage 2 hypertension. Clin Ther. 2007;29:279-289.

19. Alleman Y, Fraile B, Lambert M, Barbier M, Ferber PH, Izzo JL. Previous monotherapy: The Exforge in Failure After Single Therapy (EX-FAST) Study J Clin Hypertens (Greenwich). 2008;10:185-194.

20. Chrysant SG, Melino M, Karki S, et al. The combination of olmesartan medoxomil and amlodipine besylate in controlling high blood pressure: $\mathrm{COACH}$, a randomized double-blind, placebo-controlled, 8-week factorial efficacy and safety study. Clin Ther. 2008;30:587-604. 
21. Littlejohn TW, Majul CR, Olvera R, et al. Results of treatment with telmisartan-amlodipine in hypertensive patients. J Clin Hypertens (Greenwich). 2009;11:207-213.

22. Schmieder RE, Philipp T, Guerediaga J, et al. Long-term antihypertensive efficacy and safety of the oral direct renin inhibitor aliskiren. A 12-Month randomized, double-blind comparator trial with hydrochlorothiazide. Circulation. 2009;119:417-425.

23. Littlejohn TW, Trenkwalder P, Hollanders G, Zhao Y, Liao W. Long-term safety, tolerability and efficacy of combination therapy with aliskiren and amlodipine in patients with hypertension. Curr Med Res Opin. 2009;25:951-959.

24. Gasic S, Wagner O, Fasching P, et al. Fosinopril decreases levels of soluble vascular cell adhesion molecule-1 in borderline hypertensive type 2 diabetic patients with microalbuminuria. Am J Hypertens. 1999;12:217-222.

25. Park JK, Fiebeler A, Muller DN, et al. Lacidipine inhibits adhesion molecule and oxidase expression independent of blood pressure reduction in angiotensin-induced vascular injury. Hypertension. 2002;39:680-689.

26. Siragy HM, Xue Ch, Webb RL. Beneficial effects of combined benazepril-amlodipine on cardiac nitric oxide, cGMP, and TNF- $\alpha$ production after cardiac ischemia. J Cardiovasc Pharmacol. 2006;47: 636-642.

27. Rubio-Guerra AF, Vargas-Robles H, Vargas-Ayala G, RodríguezLopez L, Escalante-Acosta BA. The effect of trandolapril and its fixeddose combination with verapamil on circulating adhesion molecules levels in hypertensive patients with type 2 diabetes. Clin Exp Hypertens. 2008;30:682-688

28. Rubio AF, Vargas H, Lozano JJ, Escalante BA. Corrrelation between circulating adhesión molecules levels and albuminuria in type 2 diabetic hypertensive patients. Kidney Blood Press Res. 2009;32:106-109.

29. Bakris GL, Molitch M, Hewkin A, et al. Differences in glucose tolerance between fixed-dose antihypertensive drug combinations in people with metabolic syndrome. Diabetes Care. 2006;29:2592-2597.

30. Bakris GL, Molitch M, Sowers J, et al. Reversal of new onset diabetes by nondiuretic based fixed-dose antihypertensive drug combinations. Results of STAR 6-month extension (STAR-LET). J Cardiomet Syndr. 2008;3:18-25.

31. Rubio AF, Arceo A, Vargas G, Rodríguez L, Lozano J, Treviño C. The Effect of trandolapril and its fixed-dose combination with verapamil on proteinuria in normotensive adults with type 2 diabetes. Diabetes Care. 2004;27:1688-1691.

32. Rubio-Guerra AF, Vargas-Robles H, Vargas-Ayala G, RodríguezLopez L, Escalante-Acosta BA. The effect of trandolapril and its fixed-dose combination with verapamil on resistin levels in hypertensive patients with type 2 diabetes. J Hypertens. 2008;26:S476.

33. Takata Y, Osawa H, Kurata M, et al. Hyperresistinemia is associated with coexistence of hypertension and type 2 diabetes. Hypertension. 2008;51:534-539.

34. Roca-Cusachs A, Schmieder RE, Triposkiadis F, et al. Efficacy of manidipine/delapril versus losartan/hydrochlorothiazide fixed combinations in patients with hypertension and diabetes. $J$ Hypertens. $2008 ; 26: 813-818$
35. Tatti P, Guarisco R, Pahor M, et al. Outcome results of the Fosinopril versus amlodipine cardiovascular events randomized trial (FACET) in patients with hypertension and NIDDM. Diabetes Care. 1998;21:597-602.

36. Winer N, Folker A, Murphy JA, et al. Effect of fixed-dose ACE-inhibitor/ calcium channel blocker combination therapy vs. ACE-inhibitor monotherapy on arterial compliance in hypertensive patients with type 2 diabetes. Prev Cardiol. 2005;8:87-92.

37. Gross JL, De Azevedo MJ, Silveiro SP. Diabetic nephropathy: diagnosis, prevention and treatment. Diabetes Care. 2005;28:176-188.

38. Bakris GL, Weir MR, Secic M, Campbell B, Weis-McNulty A. Differential effects of calcium antagonist subclasses on markers of nephropathy progression. Kidney Int. 2004;65:1991-2002.

39. Bakris G, Weir MR, DeQuatro V, Mc-Mahon FG. Effects of an ACE inhibitor/calcium antagonist combination on proteinuria in diabetic nephropathy. Kidney Int. 1998;54:1283-1289.

40. Rubio AF, Treviño CJ, Vargas G, Narváez JL, Lozano JJ, Rodríguez L. Renoprotective effects of the combination trandolapril/verapamil in patients with type 2 diabetes mellitus and hypertension. Clin Drug Invest. 2002;22:541-546.

41. Ruggenenti P, Fassi A, Ilieva AP. Preventing microalbuminuria in type 2 diabetic patients. $N$ Engl J Med. 2004:351:1941-1951.

42. Jasik M, Niebisz AB, Kosior DA, Karnafel W. Nephroprotective effect of trandolapril and verapamil in normotensive type 1 diabetics - a 12-month follow-up study. Diabetologia Doświadczalna i Kliniczna. 2006;6:6-10.

43. Bakris GL, Toto RD, McCullough PA, Tocha R, Purkayastha D, Davis P; On behalf of the GUARD (Gauging Albuminuria Reduction With Lotrel in Diabetic Patients With Hypertension) Study Investigators. Effects of different ACE inhibitor combinations on albuminuria: results of the GUARD study. Kidney Int. 2008;73:1303-1309.

44. Fogari R, Preti P, Zoppi A, et al. Effects of amlodipine fosinopril combination on microalbuminuria in hypertensive type 2 diabetic patients. Am J Hypertens. 2002;15:1042-1049.

45. Toto RD, Tian M, Fakouhi K, Champion A, Bacher P. Effects of calcium channel blockers on proteinuria in patients with diabetic nephropathy. J Clin Hypertens (Greenwich). 2008;10:761-769.

46. Boero R, Rollino C, Massara C, Berto IM, Perosa P, Vagelli G. The verapamil versus amlodipine in nondiabetic nephropathies treated with Trandolapril (VVANNTT) study. Am J Kidney Dis. 2003;42:67-75.

47. Giunti S, Cooper M. Management strategies for patients with hypertension and diabetes: why combination therapy is critical. JClin Hypertens (Greenwich). 2006;8:108-113.

48. Mann JF, Schmieder RE, McQueen M, Dyal L, Schumacher H. Renal outcomes with telmisartan, ramipril, or both, in people at high vascular risk (the ONTARGET study): a multicentre, randomised, double-blind, controlled trial. Lancet. 2008;372:547-553.

49. Bangalore S, Kamalakkannan G, Parkar S, Messerli FH. Fixed-dose combinations improve compliance: a meta-analysis. Am J Med. 2007;120:713-719.
Integrated Blood Pressure Control

\section{Publish your work in this journal}

Integrated Blood Pressure Control is an international, peer-reviewed open-access journal focusing on the integrated approach to managing hypertension and risk reduction. Treating the patient and comorbidities together with diet and lifestyle modification and optimizing healthcare resources through a multidisciplinary team approach constitute key

\section{Dovepress}

features of the journal. This journal is indexed on American Chemical Society's Chemical Abstracts Service (CAS). The manuscript management system is completely online and includes a very quick and fair peerreview system, which is all easy to use. Visit http://www.dovepress.com/ testimonials.php to read real quotes from published authors. 